\title{
Doctors who retire early often met with scorn
}

- Cite as: CMAJ 2018 April 9;190:E449-50. doi: 10.1503/cmaj.109-5564

Posted on cmajnews.com on Mar. 22, 2018.

Y ou studied hard in university, put in long hours early in your career, lived below your means, saved a large portion of your income, and now you're financially independent and able to retire early. For many professionals, this is the ultimate success story. Not so for doctors. Many physicians who exit the profession while relatively young are more likely to receive scorn than praise.

"Yes, they do get criticized," said Dr. James Dahle, an emergency physician in Utah and founder of The White Coat Investor. "Patients don't like losing their doctors and having to find a new one, hospitals and physician groups don't like to recruit and hire, colleagues don't like to take more call and are often envious. Some view retiring early as a lazy, selfish choice."

A recent post on a forum on Dahle's website illustrates what some doctors experience when they announce their retirement before they are seniors. A family physician described what happened after he decided to retire before age 55, after 23 years of practice. "As I have been announcing my impending retirement later this year, I have been met with almost universal anger, disdain and dejection by my patient population with the words you are too young to retire echoing endlessly through the halls," wrote the physician, who did not disclose a name. "This is a somewhat disappointing end to a career as the congratulatory statements are few and far between, making that last day not soon enough."

According to Dahle, one reason doctors who retire early aren't viewed like other people who successfully escape the "rat race" while still young is that physicians are held to a different standard than other professionals. "There are a lot of expectations on docs that aren't fair - be available $24 / 7$, don't go on vacation, pay more for licences and education, give more to charity and other needs, work for free," said Dahle. "Some docs get sick of it and go do something else. Some get sick of it and just retire. Most stick it out and deal with it, hopefully making small changes that reduce its impact and the subsequent burnout."

Another physician, Dr. Valerie Jones, retired at age 37 , only seven years after

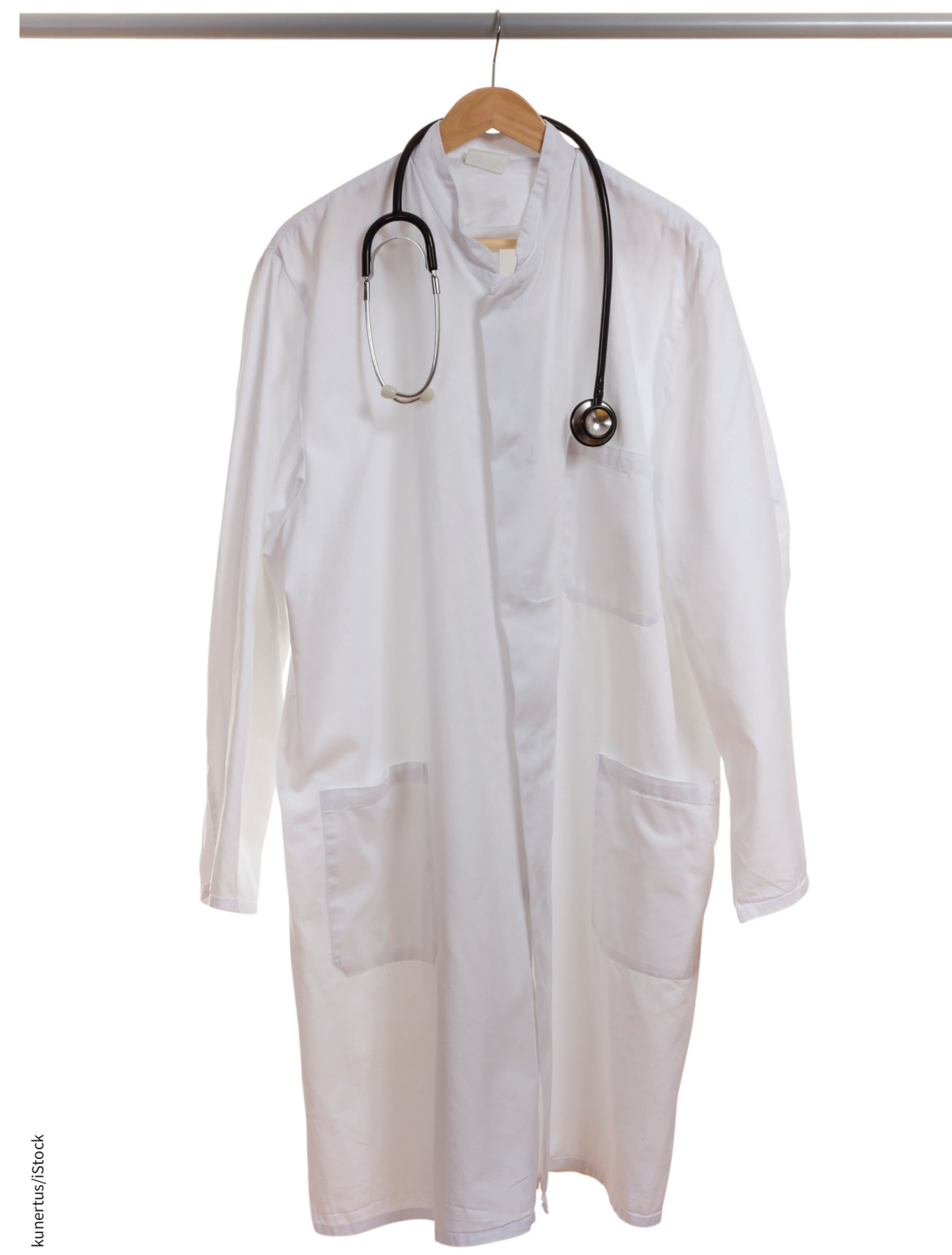

Doctors who hang up their stethoscopes while still young aren't likely to hear praise from patients or colleagues. 
completing her residency in obstetrics and gynecology at Johns Hopkins in Maryland. "A health scare made me realize some truths about the medical system that emboldened me to leave," said Jones. "I have received some negative feedback, but surprisingly it is from other physicians [usually older]."

In a blog post titled "Is it ethical to retire early from a career in medicine?" Jones said she had intended to work in medicine well into her $60 \mathrm{~s}$. But after losing a third of her left lung to remove a benign mass, Jones began to re-evaluate her "hamster wheel" of a life. She had also become disillusioned about the health care system the loss of physician autonomy, the emphasis on productivity and cost-effectiveness over quality of care, and the litigious nature of practising medicine in the US. So she decided to retire decades earlier than she had originally planned.

"I have since learned that many feel this is not an appropriate thing to do in your late 30 s. There is the argument that I owe a debt to society now that I have the skills acquired from all of those years of training," wrote Jones. "My response to the ethics of my decision to retire early: If you pay for the privilege of a medical degree and work hard to pay off this debt, should it be your decision if you want to continue to practise?"

Some doctors may want to leave the profession because the work is physically and emotionally draining, and the "red tape is thick and getting thicker," according to the doctor behind the Physician on FIRE blog, which has the tagline Financial Independence, Retire Early. "Burnout is on the rise, and some people are looking for an escape when they realize the career they envisioned is not the one they've got," said the physician, who requested anonymity. “Retiring isn't the only answer, but reaching financial independence early gives a physician many options, including parttime work or a less demanding schedule."

Ultimately, physicians should do what is best for themselves and their families, said the doctor behind Physician on FIRE. "Patients matter too, of course, but if you believe you're irreplaceable, you may need to check your ego."

Of course, retiring early is not an option for many physicians, according to Dr. Tarang Patel, a radiologist in Arizona and host of the podcast Doctor Money Matters. As in Canada, most doctors in the US have lengthy training periods and large student loans. Many don't start earning much until their early $30 \mathrm{~s}$. Also, physicians have traditionally failed to devote much energy to personal finance, though in the past "were able to prosper despite mistakes because of their higher incomes," said Patel. "However, the debt that most physicians face now is unimaginable to most older physicians, and therefore these younger physicians cannot afford the luxury of financial errors in the way previous generations could."

Roger Collier, CMAJ 